\title{
The Relationship of Family Affective Climate, Self- effectiveness, Personal-SocialAdjustment with Academic Achievement of University Students: A Study in Islamic Azad University, Ahvaz, Iran
}

\author{
Sahar Safarzadeh ${ }^{1^{*}}$ \\ 1. Department of Psychology, Ahvaz Branch, Islamic Azad University, Ahvaz, Iran.
}

Citation: Safarzadeh, S. (2016). The Relationship of Family Affective Climate, Self-effectiveness, Personal-Social Adjustment with Academic Achievement of University Students: A Study in Islamic Azad University, Ahvaz, Iran. Journal of Practice in Clinical Psychology, 4(3), 167-172. http://dx.crossref.org/10.15412/J.JPCP.06040304

dol: http://dx.crossref.org/10.15412/J.JPCP.06040304

\section{Article info:}

Received: 15 Jan. 2016

Accepted: 29 Apr. 2016

Keywords:

Family relations, Self-efficacy, Social adjustment, Educational status

\begin{abstract}
Objective: This research aimed to investigate the relationship of family affective climate, self-effectiveness, and personal-social adjustment variables with academic achievement of university students in Islamic Azad University, Ahvaz branch, Ahvaz, Iran.

Methods: The research sample included 300 individuals ( 150 females and 150 males) who were selected through random stratified sampling method. California personal-social adjustment, Scherer and Adams self-effectiveness, and family's affective climate questionnaires were administered to collect the data. Correlation coefficient and linear regression analysis were used for analyzing the data.

Results: The results of the data analysis indicated that there is a significant relationship between variables of family's affective climate, personal and social adjustment, and self-effectiveness with academic achievement of students $(\mathrm{P}<0.001)$. Furthermore, the results of linear regression analysis indicated that the variables of self-effectiveness, personal and social adjustment, and family's affective climate were significant predictors of academic achievement.
\end{abstract}

Conclusion: Improving student's self-effectiveness, personal-social adjustment, and family's affective climate may have positive influences on their academic achievement.

\section{Introduction}

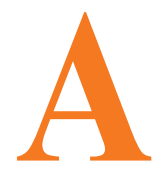

cademic achievement is one of the important issues that form the foundation of educational and psychological research (Brown \& Cross, 1997). During the last three decades, the educational experts have put the effective factors of academic achievement in the limelight. Attending to this issue is considered as the top priority of educational programs' development (Hattie \& Timperley, 2007). According to Lawin (1967, cited in Gholami, 2005), academic achievement is the representation of a learner's position. This position which may refer to a score for a lesson or GPA for

\footnotetext{
* Corresponding Author:

Sahar Safarzadeh, MSc.

Address: Department of Psychology, Faculty of Humanities, Ahvaz Branch, Islamic Azad University, Ahvaz, Iran.

Tel: +98 (916) 3049476

E-mail: safarzadeh1152@yahoo.com
} 
a set of lessons can be influenced by a number of factors such as family's affective climate. In a number of studies such as Nailing (2010), it was shown that students' academic achievement is related to a number of family features such as parents' beliefs and expectations, disciplinary acts, parents' interventions, family's affective climate, and the accessible resources. Family's affective climate means how to relate, behave, and share opinions with other members of the family, which can be effective in students' psychological and behavioral health and academic achievement.

Among the other effective factors in academic achievement is self-effectiveness. Bandura (1997) defined selfeffectiveness as the individual's perception and judgment about his/her skills and abilities to do the necessary jobs in specific situations (Pajares, 1996). Moreover, self-effectiveness is the reassurance that the individual successfully performs a specific behavior and achieves the desired consequence (Bandura \& Schuk, 2004). The individual's self-effectiveness determines his/her level of motivation by controlling his or her levels of attempts and the perseverance needed for tackling the barriers. On facing with difficulties such as achievement in education, those who do not believe in their abilities decrease their effort and employ low-level strategies (Bandura, 2001).

Another factor that can influence the educational achievement is personal-social adjustment. According to Deman, Hall, and Stout (1991), this factor is the individual's adjustment toward the social environment. The research by Mir Moshtaghi (2005) indicated that there is significant relationship between the components of social adjustment, self-regulation, and academic achievement. Thus, this factor can improve the individuals' life quality and increase their performance in different aspects such as academic achievement. Some studies have been carried out in this area which will be explained in the following paragraphs. Students' academic motivation can be affected by the family emotional climate. Feeling of confidence and security, encouragement, confirmation, love, and joint experience between husband and wife, between parents and children, and between children themselves are principles of family communications that constitute family climate (Emerson, Fear, Fox, \& Sanders, 2012).

The results of the research by Hadsell (2012) and Seçer, Çeliköz, Koçyiğit, Seçer, and Kayılı (2010) indicated that there was a significant relationship between the goals of family relationships and self-effectiveness with academic achievement. Chang and Solomon (2010) showed that self-effectiveness was significantly and positively correlated to academic achievement. Panaghi,
Ahmadabadi, Ghahari and Mohammadi (2013) as well as Akanbi and Ogundokun (2006) demonstrated that participants having undergone self-effectiveness training showed better academic performances compared to the control group. Doostian et al. (2014) taught students self-regulation along with effective and useful tips to improve their academic achievement and performance. The research by Allison (2005) showed the same results. Many researchers tried to find some factors that can affect students' performance and achievement level. So they investigated the effect of family climate and similar variables such as academic self-efficacy in the educational institutes in statutes (Smith, 2012; Hoy, Tarter, \& Hoy, 2006; Macneil, Prater, \& Busch, 2009), On the other hand, there were some students that have found a positive relationship between self-efficacy grades in college (Chemers, Hu, \& Garcia, 2011; Greene, Miller, Crowson, Duke, \& Akey, 2004; Zajacova, Lynch, \& Espenshade, 2005; Sharm \& Silbereisen, 2007; Akomolafe, Ogunmakin, \& Fasooto, 2013).

The results of the research by Zadehmohammad, Abedi, and Moradi Panah (2013) and Carroll et al. (2009) indicated that self-effectiveness and personal-social improvement have significant and positive relationship with students' academic achievement. Mir Moshtaghi (2005) also indicated that there was a significant relationship between the components of social adjustment and self-regulation with students' academic achievement. Roopnarine et al. (2006) concluded that authoritarian parenting style is significantly and negatively correlated with acquired skills and the vocabulary repertoire of the child, while father's authoritative style, his educational reaction with the child at home, and the constant contact with the child's school have positive relationship with the development of such skills and also social behaviors in the child.

Sonnette, Patrick and Melissa (2009) indicated that the existence of relationships among the insecure parents was indirectly correlated with poor educational achievement and negative information processing in terms of stressful events with peers. Rubin and Mills (2005), Kinsfogel and Grych (2004), and Ward (2004) have carried out different research on family's affective climate and the success of children. The variable of academic performance is multifaceted and influenced by many factors. The development of research and their findings in an educational level negates any kinds of oversimplified thinking (Brophy, 2002). Based on these considerations, psychological adjustment depends on functional family relationship, further studies should investigate the attitude of this association based on family environment variables. Based on the present study, family environ- 
ment predicts psychological adjustment in adolescence using structural equation modeling, so it's main objective was to test a theoretical model.

The result of this research benefits teachers and educational trainers. Hence, the present research aimed to investigate the aspects that are still controversial in the literature. These aspect are as follows: 1) Whether family climate is related to academic achievement, 2) Whether self-effectiveness is related to academic achievement, 3) Whether personal-social adjustment is related to academic achievement, and 4) Whether family's affective climate, self-effectiveness, and personal-social adjustment are significant predictors of academic achievement among the university students.

\section{Methods}

The present research had a cross-sectional design. The study instrument was administered at the participants' classroom.

The statistical population included all university students. The research sample comprised 300 (150 females, 150 males) university students who were selected through random stratified sampling method. First, a list of the faculties was selected and a number of male and female students were selected from each faculty according to the frequency proportion of the faculties and responses to the questionnaires. The students were 50\% females and 50\% males. Their age ranged from 19 to 31 years (mean $=24.1$, $\mathrm{SD}=3.14$ years). About $47 \%$ of them belonged to middlelow-class, while $50 \%$ constituted middle-class students and the remainder $3 \%$ were of high-class. This selection closely corresponded to a representative public university sample, according to criteria of the Islamic Azad University of Ahvaz branch. The response rate was $100 \%$. Informed consents were obtained from participants before giving questionnaires. Participants were assured that their demographic information would be confidential and they could leave the research whenever they want. Also, all participant's questions were answered during research.

They are sharing in average minimum 15. The students who had drag abuse and lack of mental balance were deleted from sample. Then, they answered the questionnaires.

General self-efficacy scale (GSES) is a 17-item questionnaire, designed and developed by Sherer and Adams (1983, cited in Barati Bakhtiyari, 1996). Barati Bakhtiyari (1996) reported its Cronbach $\alpha$ coefficient and test-retest reliability as 0.79 and 0.37 . Moreover, its correlation with self-efficacy and exam anxiety indicated that, there is significant relationship between self-effec- tiveness and exam anxiety which equals 0.61 . Reviewing various organizational studies, Chen, Gully, \& Eden, (2001) showed internal consistency reliabilities of GSES to be moderate to high ( 0.76 to 0.89 ) by reviewing various organizational studies. Their statistical society included university students and managers in two of their studies. By taking temporal stability of GSES, Chen and Gully found (as cited in Chen, et al., 2001) a low testretest estimate $(r=0.23)$ across only 3 weeks. Although, Chen et al. found high test-retest reliability $(\mathrm{r}=0.74)$.

General Self-Efficacy Scale is a 17-item questionnaire. Barati Bakhtiyari (1996) reported its Cronbach $\alpha$ coefficient and test-retest reliability as 0.79 and 0.37 , respectively. Moreover, its correlation with self-efficacy and exam anxiety indicated a significant relationship between self-effectiveness and exam anxiety, which equals 0.61 .

California social-personal adjustment consists of 180 two-option (Yes or No) items. The reliability coefficient in the research by Masoudi Nezhad (1992, cited in Mousavi Shoushtari, Haghighi, \& Shokr Kon, 1997) was done on gifted students and equaled 0.86 for personal adjustment and 0.78 for social adjustment. In order to assess the reliability of the test, Mousavi Shoushtari et al. (1997) created a criterion questionnaire, which deals with the assessment of the areas of this scale. Results indicated that the reliability of the test is acceptable and the results can be trusted $(\mathrm{r}=0.70)$.

Finally, grade point average (GPA) was used as an indicator of the student's academic achievement. The data were analyzed using descriptive statistics (means, standard deviations) and inferential statistics (the Pearson correlation and regression analysis). The internal consistency of the scales was also analyzed (The Cronbach $\alpha$ ).

\section{Results}

The descriptive indexes of the research variables are presented as means and standard deviations in Table 1.

Research hypothesis were as follows:

First hypothesis: there is a significant relationship between family's affective climate and students' academic achievement.

Second hypothesis: there is a significant relationship between self-effectiveness and students' academic achievement. 
Table 1. Descriptive indexes of the research variables.

\begin{tabular}{ccccc}
\hline Variable & Min & Max & Mean & SD \\
\hline Academic achievement & 11.80 & 20 & 15.81 & 2.604 \\
\hline Family's affective climate & 24 & 83 & 50.81 & 17.044 \\
Self-effectiveness & 30 & 90 & 64.54 & 20.532 \\
Personal-social adjustment & 66 & 188 & 136.26 & 45.201 \\
\hline
\end{tabular}

Table 2. Correlation matrix of the independent variables (predictors) and dependent variable (criterion).

\begin{tabular}{|c|c|c|c|c|}
\hline & $\begin{array}{c}\text { Academic } \\
\text { achievement }\end{array}$ & $\begin{array}{l}\text { Family's affective } \\
\text { climate }\end{array}$ & Self-effectiveness & $\begin{array}{c}\text { Personal-social } \\
\text { adjustment }\end{array}$ \\
\hline Academic achievement & $\begin{array}{c}r=1 \\
P \leq 0.01\end{array}$ & $\begin{array}{l}r=0.676 \\
P \leq 0.01\end{array}$ & $\begin{array}{l}r=0.712 \\
P \leq 0.01\end{array}$ & $\begin{array}{r}r=0.700 \\
P \leq 0.01\end{array}$ \\
\hline Family's affective climate & - & $\begin{array}{c}r=1 \\
P \leq 0.01\end{array}$ & $\begin{array}{l}r=0.786 \\
P \leq 0.01\end{array}$ & $\begin{array}{l}r=0.727 \\
P \leq 0.01\end{array}$ \\
\hline Self-effectiveness & - & - & $\begin{array}{c}r=1 \\
P \leq 0.01\end{array}$ & $\begin{array}{l}r=0.702 \\
P \leq 0.01\end{array}$ \\
\hline Personal-Social adjustment & - & - & - & $\begin{array}{c}r=1 \\
P \leq 0.01\end{array}$ \\
\hline
\end{tabular}

PRACTIE in CLINICAL PSYH $O$ LOGY

Table 3. Results of multiple regression analysis.

\begin{tabular}{lcccccccc}
\hline Criterion variable & Predictor variables & $\mathbf{R}$ & $\mathbf{R}^{2}$ & $\mathbf{F}$ & $\mathbf{P}$ & $\boldsymbol{\beta}$ & $\mathbf{t}$ & $\mathbf{P}$ \\
\hline & $\begin{array}{c}\text { Self-effectiveness } \\
\text { Personal-Social adjust- } \\
\text { ment }\end{array}$ & 0.770 & 0.593 & 143.552 & 0.01 & 0.343 & 5.662 & 0.01 \\
$\begin{array}{c}\text { Academic achieve- } \\
\text { ment }\end{array}$ & $\begin{array}{c}\text { Family's affective envi- } \\
\text { ronment }\end{array}$ & & & & & 0.146 & 2.225 & 0.027 \\
\hline
\end{tabular}

PRANICAL PSYCH $\oplus$ LOGY

Third hypothesis: there is a significant relationship between personal-social adjustment and students' academic achievement.

Fourth hypothesis: family's affective climate, self-effectiveness, and personal-social adjustment will predict academic achievement of students.

To analyze the relationship between family's affective climate, self-effectiveness, and personal-social adjustment with students' academic achievement, the Pearson correlations were used. Results are shown in Table 2. As observed in Table 2, there is a significant and positive relationship between academic achievement and variables of family's affective climate, self-effectiveness, and personal-social adjustment. Therefore, enough support was found for the research's 3 hypotheses $(\mathrm{P}<0.01)$. To analyze the prediction of academic achievement based on family's affective climate, self-effectiveness, and personal-social, the adjustment multiple linear regression was used (Table 3). A significant regression coefficient was found $(\mathrm{F}=143.552, \mathrm{P}<0.0001)$ with an $\mathrm{R}^{2}$ of 0.593 . 
All 3 prediction variables of family's affective climate, self-effectiveness, and personal-social adjustment were significant predictors of academic achievement.

\section{Discussion}

As observed in Table 2, there is significant and positive relationship between family's affective climate, selfeffectiveness, personal-social adjustment and academic achievement. Therefore, enough support was found for the research's three hypotheses $(\mathrm{P}<0.01)$. Therefore, the first, second and third hypotheses of the research were confirmed. With regard to results of multiple regression analysis (Table 3), we can conclude that the variables of self-effectiveness, personal-social adjustment, and family's affective climate are good predictors of the dependent variable (academic achievement); therefore, the fourth hypothesis is also confirmed. The results of the present research are in line with the results of the studies carried out by Doostian et al. (2014), Zadehmohammad et al. (2013), Hadsell (2012), Chang and Solomon (2010), Carroll et al. (2009), and Sonnette et al. (2009).

Bandura considers self-effectiveness as a factor, which has been shaped by the interaction with the environment (possibly the parents' feedbacks and family climate) and acts like a cognitive mediator influencing the cognition, thoughts, and feelings of individuals. Therefore, when students are exposed to negative events and stressful conditions, having high self-effectiveness, help them to better achieve social personal adjustment to manage and help them become resistant against educational problems. To explain this finding, we can say in families that children's development and progress receive no positive response such as praise, love, satisfaction and acceptance from their parents, children become motivated.

As cited above, merit sensation is necessary for development of children's intrinsic motivation. Children will achieve this motivation, when their parents confirm and admire them. The most essential prerequisite for a child to achieve merit sensation and feeling of efficacy is success in academic situations. If parents pay attention to their children's progress sufficiently, they won't commit aggression and misbehavior at school and temper in order to draw parents' attention. On the other hand, inappropriate affective climate among the family members can pave the way for feelings of inefficacy which will cause lack of effective adjustment with stressful life events and symptoms of disease (Jex \& Bliese, 1999). Moreover, individuals who have high levels of self-effectiveness make more efforts and have more perseverance in doing the educational and social assignments and believe in their abilities which will lead to even higher self-efficacy and adjustment (Cassaday, 2004). This point confirms the results of the present research.

A limitation in this study was the use of self-report data which increases the possibility of common answers. Finally, we suggest that the role of academic achievement be investigated in different academic aspects and causes of creating and achieving this condition be brought to light. Future work may seek to find the specific form of interventions that increase academic achievement. The result of this research benefits teachers and educational trainers.

\section{Acknowledgments}

The authors thank all people who assisted in performing the study and accessing the data. In this research, subjects' information remains secret and participates for subject was voluntarily.

\section{Conflict of Interests}

The authors declared no conflict of interests.

\section{References}

Akanbi, S. T., \& Ogundokun, M. O, (2006). Effectiveness of selfefficacy strategies as method of reducing test anxiety of student nurses in Ogbomosho north local government area, Oyo State, Nigeria, African. Journal of Cross-Cultural Psychology and Sport Facilitation, 18(1), 18-26.

Akomolafe, M. J., Ogunmakin, A. O., \& Fasoota, G. M. (2013). The role of academic self-efficacy, academic motivation and academic self-concept in predicting secondary school students' academic performance. Journal of Educational and Social Research, 3(2), 335-342.

Alison, R. (2005). The relationship of positive and negative perfectionism to academic achievement, Achievement motivation, and well-be ing in tertiary students. Canterbury: University of Canterbury.

Bandura, A. (1997). Self-efficacy: the exercise of control. New York: Freeman.

Bandura, A. (2001). Guide for constructing self-efficacy scales. Stanford, C.A.: Stanford University.

Bandura, A., \& Schuk, D. H. (2004). Cultivating competence, self-efficacy and intrinsic interest through proximal selfmotivation. Journal of Personality and Social Psychology, 41(3), 586-98.

Barati Bakhtiyari, S. (1996). [Simple and multiple relationships between self-efficacy, self-care, self-esteem and educational performance of students (Persian)] (MA thesis). Ahvaz: Shahid Chamran University. 
Brophy, J. (2002). Elementary teachers' perfections and types of problem student. East Lansing, M.I.: Institute for Research on Teaching, Michigan State University.

Brown, N. W., \& Cross, J. E. (1997). Coping resources and family environment for female engineering students. College Student Journal, 31(2), 282-90.

Carroll, A. M., Houghton, S., Wood, R., Unsworth, K., Hattie, J., Gordon, L., et al. (2009). Self- efficacy and academic achievement in Australian high school student: the mediating effects of academic as operations and delinquency. Journal of Adolescence, 32(2), 797-817.

Cassaday, J. C. (2004). The influence of cognitive test anxiety across the learning-testing cycle. Learning and Instruction, 14(6), 569-92.

Chang, B. G., \& Solomon, J. (2010). Stereotype threat test anxiety and specific self-efficacy as predictors of promotion exam performance. Group \& Organization Management, 35(4), 77-107.

Chemers, M. M., Hu, L., \& Garcia, B. F. (2011). Academic selfefficacy and first-year college student performance and adjustment. Journal of Educational Psychology, 93(1), 55-64.

Deman, A. F., Hall, V., \& Stout, D. (1991). Neurotic nucleus and test anxiety. Journal of Psychology, 125(6), 671-75.

Chen, G., Gully, S. M., \& Eden, D. (2001). Validation of a new general self-efficacy scale. Organizational Research Methods, $4(1), 62-68$.

Doostian, Y., Fattahi, S., Goudini, A. A., Azami, Y., Massah, O., \& Daneshmand, R. (2014). The Effectiveness of self-regulation in students' academic achievement motivation. Journal of Practice in Clinical Psychology, 2(4), 261-70.

Emerson, L., Fear, J., Fox, S., \& Sanders, E. (2012). Parental engagement in learning and schooling: lessons from research. Canberra: Family-School and Community Partnerships Bureau.

Gholami, Y. (2005). [Comparative investigation of the motive of progress and the self-concept of the eighth grade of students of different countries with academic (Persian)] (MA thesis). Ahvaz: Islamic Azad University.

Greene, B. A., Miller, R. B., Crowson, H. M., Duke, B. L., \& Akey, K. L. (2004). Predicting high school students' cognitive engagement and achievement: contributions of classroom perceptions and motivation. Contemporary Educational Psychology, 29(4), 462-82.

Hadsell, L. (2012). Achievement goals, locus of control, and academic success and effort in introductory and intermediacy microeconomics. New York: University of New York.

Hattie, A., \& Timperley, H. (2007). The power of feedback. Review of Education Research, 77(1), 81-112.

Hoy, W., Tarter, C., \& Hoy, A. (2006). Academic optimism of schools: a force for student achievement. American Educational Research Journal, 43(3), 425-46.

Jex, S. M., \& Bliese, P. D. (1999). Efficacy beliefs as moderator of the impact of work-related stress ors: Multilevel study. Journal of Applied Psychology, 84(1), 359-61

Kinsfogel, M., \& Grych, H. (2004). Inter-parental conflict and adolescent dating relationships. Journal of Family Psychology, 18(3), 505-15.
Kouti, F., Rajabi, Gh., \& Soudani, M. (2007). [Relationship between family's affective climate, social support and general health among the first graders of the high schools located in Ahvaz city (Persian)]. Journal of Social Psychology (New Findings in Psychology), 2(5), 4-18.

Macneil, A. J., Prater, D. L., \& Busch, S. (2009). The effect of school culture and climate on student achievement. International Journal of Leadership in Education, 12(1), 73-84.

Mir Moshtaghi, Sh. (2005). [Investigation and comparison of selfeffectiveness, self-regulation and academic achievement of third graders of high schools in the majors of mathematics and humanity (Persian)] (MA thesis). Tehran: Al-Zahra University.

Mousavi Shoushtari, M., Haghighi, J., \& Shokr Kon, H. (1997) [Relationship between family's affective climate, personal-social adjustment and academic achievement of the third graders in the junior high schools of Ahvaz (Persian)] (MA thesis). Ahvaz: Islamic Azad University.

Nailing, X. (2010). Family factors and student outcomes. Santa Monica: Rand Corporation Publication.

Pajares, F. (1996). Self-efficacy beliefs in achievement settings. Review of Educational Research, 66(4), 543-78.

Panaghi, L., Ahmadabadi, Z., Ghahari, S., \& Mohammadi, S. (2013). Social support, coping mechanisms on mental health of women suffering from spouse abuse. Journal of Practice in Clinical Psychology, 1(1), 9-15.

Rubin, K. H., \& Mills, R. L. (2005). Maternal beliefs about adaptive and maladaptive social behaviors in normal, aggressive and withdrawn preschools. Journal of Abnormal Psychology, 18(4), 419-35.

Seçer, Z., Çeliköz, N., Koçyiğit, S., Seçer, F., \& Kayıll, G. (2010) Social skills and problem behaviours of children with different cognitive styles who attend preschool education. Australian Journal of Guidance and Counselling, 20(1), 91-98.

Sharm, D., \& Silbereisen, R. K. (2007). Revisiting an era in Germany from the perspective of adolescents in mother-headed single-parent families. International Journal of Psychology, 42(1), 46-58.

Smith, A. (2012). The organizational health of high schools and student proficiency in mathematics. International Journal of Educational Management, 16(2), 98-104.

Sonnette M. B., Patrick T. D., \& Melissa L. S. A., (2009). Children's representation of family relationships, peer information, and school adjustment. Developmental Psychology, 45(6), 1740-751.

Ward, S. M. (2004). Our children's social skills. New York: ERIC Document Reproduction Service.

Zadehmohammad, A., Abedi, A. R., \& Moradi Panah, F. (2013). Group narrative therapy on self-esteem and self-efficacy of male orphan adolescents. Journal of Practice in Clinical Psychology, 1(1), 55-60.

Zajacova, A., Lynch, S. M., \& Espenshade, T. J. (2005). Self-efficacy, stress, and academic success in college. Research in Higher Education, 46(6), 677-706. 